\title{
Absenteeism, childcare and the effectiveness of pension reforms
}

\author{
Flavia Coda Moscarola ${ }^{1 *}$, Elsa Fornero ${ }^{1}$ and Steinar Strøm²
}

\author{
* Correspondence: \\ flavia.codamoscarola@carloalberto.org \\ ${ }^{1}$ University of Turin and CeRP-Collegio \\ Carlo Alberto, Corso Unione Sovietica \\ 218bis, 10134 Torino, Italy \\ Full list of author information is \\ available at the end of the article
}

\begin{abstract}
Both economic and epidemiological literature have shown that perceived high strain at work and lack of social infrastructures are good predictors of sick leave. The latter is particularly relevant in countries where facilities for children and care services are scarce and women are asked to fill the gap. The Italian 2011 pension reform significantly restricted age and seniority requirements for retirement, especially for women in private employment. We investigated whether older Italian employed women reacted to the postponement of retirement by increasing their sick leave. The empirical analysis offers unequivocal evidence that this has indeed been the case, in particular, for low-income grandmothers living in regions with a poor supply of childcare services. Radical reforms risk losing some of their effectiveness if they are not accompanied by parallel measures designed to introduce the welfare provisions previously indirectly and inadequately provided by the pension system, such as care facilities.

JEL codes: J26, J13, C33

Keywords: Pension reform, Sick leave, Childcare
\end{abstract}

\section{Introduction}

The paper investigates whether a hardening of prerequisites for retirement determines an increase in sick-leave spells taken by workers. It measures the increase by analysing the response of Italian women to the far-reaching 2011 pension reform, which-approved under the threat of a financial crisis-significantly and unexpectedly increased the effective retirement age. The focus is on middle-aged women employed in the private sector, a group who still enjoyed, before the reform, favourable retirement conditions (possibly as an implicit ex post compensation for subtle discrimination in the labour market) and who experienced, because of the rapid transition to the new rules, the sharpest restriction in the age/seniority requirements for retirement.

The aim of this paper is to look for a possible 'substitution effect' between (postponed) retirement and sick leave. The exercise is complicated by the fact that recourse to sick leave by Italian middle-aged women has potentially been influenced, in recent years, by a number of conflicting forces. On the one hand, unexpected restrictions to retirement may induce an increase in sick leave for specific health reasons or as a pretext for attending family chores, such as caring for grandchildren and/or older family members. This aspect will be the focus of the paper. 
On the other hand, Italy has gone through a severe and prolonged recession that has reduced household incomes and increased economic vulnerability. With a very sluggish labour market and high unemployment rates, lay-offs are more likely and absenceprone workers are typically among the first to be dismissed. Job loss fear can be enough to reduce absences to the absolute minimum (Leigh 1985). Moreover, the Italian labour market reform (approved a few months after the pension reform, see Fornero 2014) reduced employment protection, and economic literature has extensively documented that there is a positive correlation between employment protection and absenteeism (Ichino and Riphahn 2005). Finally, sick leave can have negative effects on individuals' working careers ${ }^{1}$ with likely consequences also for pension benefits (in Italy still largely determined, for current and quasi-retirees, according to a defined benefit (DB) formula, based upon the average salary of the final 10 years).

Our goal is to isolate the 'pure' effect of the 2011 Italian pension reform on absenteeism.

The literature on absenteeism is quite rich. Both economic and epidemiological analyses have highlighted that perceived high strain at work and poor social provisions are good predictors of sick leave (Andreassen and Kornstad 2010; Moreau et al. 2004). It has also been demonstrated that the cost of being absent significantly affects work absence behaviour (see Johansson and Palme 1996, 2002). Both sick-leave regulation and its implementation play a key role in determining individuals' absence choices. Concerning Italy, Scoppa (2010) and Scoppa and Vuri (2014) have pointed out how sick leave is higher among workers with higher seniority and more stable contracts, employed in public sector or in big private companies and living in regions with low unemployment levels. These findings, which refer to the pre-reform situation, are explained by the authors as the result of workers' opportunistic behaviour in a country with low controls and high employment protection.

The literature on the effects of pension reforms, however, has concentrated on the consequences of a change in retirement rules on wealth accumulation and savings (Attanasio and Rohwedder 2003); on work and retirement decisions of individuals and couples (Belloni and Alessie 2009; Colombino et al. 2011); on the adequacy of retirement resources; on income distribution (Fornero et al. 2010; Borella and Coda Moscarola 2006, 2011); and on long-term employment and growth (Buyse et al. 2013).

To the best of our knowledge, the effects of pension reforms on absenteeism have not yet been analysed. We found evidence of higher sick-leave absences for low-income women who were obliged by the reform to postpone retirement and who in 2011, before the reform (which was approved just before the end of the year), had already experienced a sick-leave spell. As for women who had not taken any sick leave in 2011, only grandmothers reacted to the postponement of retirement, particularly if household income is low and they are living in regions with a poor supply of childcare services, possibly as a last resort to cope with caregiving duties towards grandchildren. Their reaction is actually proportional to the number of years of delay in retirement imposed by the reform.

The remainder of the paper is organised as follows. Section 2 describes the Italian regulatory framework. Section 3 describes the empirical model. Section 4 presents the data and the descriptive statistics. Estimates on the effects of the pension reform on absenteeism are presented in Section 5. Section 6 concludes by drawing policy implications. 


\section{The Italian regulatory framework}

Since our analysis is centred on how reforms shape individuals' behaviour, we start with a concise description of the Italian retirement and sick-leave regulations, followed by an overview of the availability and use of different childcare arrangements.

\subsection{The pension system before and after the 2011 reform}

The Monti-Fornero reform (law 214/2011) - introduced at a time when it was imperative to act immediately in order to avoid a potentially devastating crisis not only for the Italian public debt but for the whole Eurozone-was the decisive stage of the very long and slow restructuring process of the Italian pension system that started in 1992, again triggered by a financial emergency. While all previous reforms had accommodated an exasperatingly long phasing in, in 2011, there was little room for gradualism, given the necessity to reduce pension expenditure in the short to medium run (Fornero 2015).

The reform introduced sharp restrictions to early retirement provisions (such as pure seniority pensions, formerly awarded almost irrespective of age) and more stringent age and seniority requirements for normal (old age) retirement. These restrictions affected women more than men because the law set to equalise requisites across gender by 2018 and because women until then had received more favourable pension treatment, including more opportunities, with respect to men, to access early retirement provisions.

One of the key features of the new reform was the immediate application, as of January 1, 2012, of the defined contribution (DC) formula, for all future seniorities and to all workers, irrespective of their time to retirement. This provision was meant to reinstate credibility to the DC formula and to do away with the hardly justifiable differentiations in pension provisions that had been created by the extremely gradual implementation of the previous reforms, which had thus shifted almost all the adjustment burden on the shoulders of the younger generation.

Additional file 1: Table S1 compares the pre- and post-reform provisions more extensively.

\subsection{Sick-leave regulations}

The Italian sick-leave regulations are based on the principle of not penalising the worker and therefore of guaranteeing both the salary and the accumulation of pension wealth in case of sickness. All illness-due absences lasting more than 1 week lead to the so-called notional contributions which, instead of being paid by the employer/employee, are financed by health-specific payroll taxes or general taxation, so that sick-leave periods are recorded for the computation of both eligibility requirements and pension benefit. Accreditation is conditional on having contributed to the Social Security scheme for more than 1 week before the start of the illness and, since 2009, has been subject to a maximum of 96 weeks in the whole working life (INPS 2013). ${ }^{2}$

\subsection{The Italian childcare system}

A heterogeneous mix of formal/informal, voluntary/compulsory elements characterises the Italian childcare system, with strong regional differences and women supplying a large part of the informal/voluntary services, sometimes acting as substitutes and more often as complements of the formal care received by children. The informal/voluntary elements prevail in the pre-school ages, mainly in the 0-3 age group, where places in 
nursery schools are in scarce supply and used on average by only one in ten children, with great heterogeneity across regions and the south underperforming. ${ }^{3}$ On the contrary, the formal/compulsory elements prevail for the 3-6 age group, with Italy ranking quite high in Europe for its childcare services: childcare for the 3-6 age group is considered an official part of the educational path, and thus more standardised; attendance is voluntary but the take-up rate is quite high.

With inadequate public supply, one would expect the market to fill the gap. Not so in Italy, where the formal provision of care from private structures (such as those organised by religious orders) is often considered an imperfect substitute, given their lower average quality and higher average costs (Del Boca et al. 2005). On the contrary, grandparents' involvement in childcare is widespread, more intense when children are small and/or do not attend day care. This support is essential to ease the integration of mothers into the labour market when formal care provision is missing or insufficient, as school hours are short with respect to the standard working day and access to parttime positions is inadequate (Ichino and Sanz de Galdeano, 2005; Del Boca et al. 2005; Keck and Saraceno, 2008).

According to Share data (waves 4 and 5), $45 \%$ of grandmothers are involved in caring for their grandchildren, almost a quarter of them on a daily basis. According to the Eusilc data (see Table 1), outside school or pre-school hours, informal caregiving provided by grandparents or other relatives is by far the most widespread source of care, while only few families avail themselves of child centres or childminders.

\section{The empirical model}

\subsection{Possible outcomes of an increase in age/seniority requirements}

Workers affected by the restrictions of a pension reform can either continue to work or withdraw from the labour market, living on savings and/or a spouse's income while waiting for their pension benefit. In what follows, we only consider those who continue their working activity. Some of them continue to work with no subsequent increase in their morbidity rate (or following the trend shown in previous years), while others resort to additional sick leave. This group may consist of workers that effectively experience worsening health, or subjectively perceive a worsening of their well-being or simply react negatively to the pension restrictions. Of course, taking sick leave requires validation by the doctor, which should in principle only be given for the first instance. However, apart from a lack of controls, there is a 'grey area' in which, in the presence

Table 1 Average hours of care outside school or pre-school hours during a usual week by care provider-Eusilc data 2010

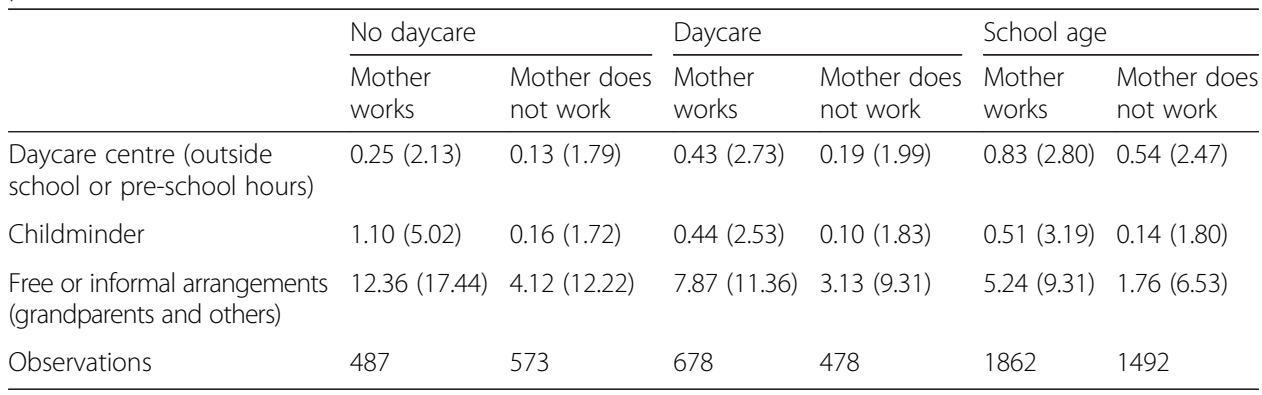

Source: Author's elaborations on Eusilc 2010 data; standard errors in parentheses 
of uncertain symptoms, it can be very difficult for doctors to refuse certification (as in the case of psychological complaints).

Whatever the reasons, our a priori assumption is that sick leave could be the response of some workers to the restrictions imposed by the pension reforms, especially in the case of individuals who had planned early retirement for circumstances that the reform could not accommodate. This does not mean we are assuming an opportunistic behaviour on the part of workers (and an accommodating behaviour on the part of doctors); on the contrary, we would like to test whether the disruption of personal life plans caused by a pension reform results in longer/more frequent sick leave.

Of course, in cases of very serious health conditions, the worker can apply for a disability pension. However, in this paper, we do not consider this, as we do not have access to the archive of disability applications. In any case, since the early 80 s, Italy has adopted a much stricter policy towards disability pensions, and their current number can be considered physiological (Ragioneria Generale dello Stato 2014).

\subsection{The econometric specification}

In order to test our hypothesis, we adopted a first differencing (FD) approach and estimated the following equation on a balanced panel referring to the years 2011 and 2012:

$$
\Delta Y_{i t}=\left(Y_{i 2012}-Y_{i 2011}\right)=T+\left(Z_{i 2012}-Z_{i 2011}\right) \gamma+\text { aTreated }_{i 2012}+\left(u_{i 2012}-u_{i 2011}\right)
$$

where $Y_{i t}$ is the number of weeks of sick leave in the year $t$ (with $t$ equal to either 2012 or 2011) for the individual $i$; $T$ is the trend dummy that is equal to 1 in 2012 and 0 otherwise; $Z_{i t}$ is a set of individual and regional time-varying explanatory variables measured at time $t$ and $u_{i t}$ is the time $t$ individual-specific error term. We used the panel dimension to compute seniority and other retirement requisites but, because of data limitations, we only considered the responses in year 2012, i.e. the 'first' reaction to the reform.

The reaction was measured by the estimated coefficient of the dummy variable Treated. Treated is equal to 1 in the case of the worker's retirement having been postponed by the 2011 pension reform, 0 if she is unaffected by the reform, i.e. belongs to the control group (the reform did not affect workers who, according to the pre-reform provisions, could retire in 2012). Treatment in year 2011 is zero for both groups. If being affected by the reform had a positive impact on the number of sick-leave weeks, $\alpha$ is positive. To better investigate the effect, we tried different specifications of the model.

\section{Data and descriptive statistics}

The analysis is based on data from an administrative data set provided by the Italian Social Security Institute (INPS), the so-called Estratti Conto archive. ${ }^{4}$ This archive collects information related to the workers' contribution periods for every INPS pension scheme (initial and final dates of each contribution period); a classification of contributions (regular employed work, sick leave, maternity leave, unemployment, etc.) and gross earnings, used to compute payrolls and pension benefits. The INPS provided a sample from this archive containing registered individuals born on the first and the ninth of each month of each year. The data are updated on December 31, 2012, which means that the sample contains information on the working lives of the selected individuals from the date of their first contribution to any of the INPS schemes up to the 
end of 2012. The archive however provides no information on seniority accrued in different pension schemes (i.e. as civil servants or as freelance professionals), making it thus impossible to get a complete picture for workers with mixed careers. ${ }^{5}$ Moreover, it only reports illness-due absences lasting 1 week or longer. It also provides very limited information on the individuals' socio-demographic characteristics, namely year of birth (and death), gender and region of residence.

We identified mothers and women in charge of informal caregiving by observing maternity and caregiving leave. We denote as 'grandmothers' those women who experienced maternity leave before 1995 . We acknowledge that not all women who took maternity leave in their youth will have actually become grandmothers, but the data do not provide for a more accurate definition.

We focused on the sub-sample of women registered in the private-sector employees' scheme (Fondo Pensione Lavoratori Dipendenti, FPLD), born between 1947 and 1959, and not yet retired in 2012 as they had not reached pension eligibility in 2011. The data provided information on this group's spells of work and sick leave from 1962 to 31st December 2012. After refining our sample by excluding some special cases, ${ }^{6}$ we ended up with a balanced panel of 25,258 women still at work in 2011 and 2012 and analysed the determinants of the variation in the length of their sick-leave spells between 2011 and 2012.

We used a simulation procedure to identify the 'treated' group, i.e. the women compelled by the reform to delay retirement. Starting from observed age and seniority in 2012, we simulated the retirement year for each woman in the sample by considering the age/seniority requisites to access either early or old-age retirement under the preand post-reform rules and under the hypothesis of a continuous (future) career. The assessment of pension requirements refers to 1st of December of each year (in some cases, this requires the month and the date of birth, which we randomly assign, further assuming that they are all born on the last day of the month). ${ }^{7}$

According to our simulations, as a consequence of the reform, about $74 \%$ of our sample experienced a 1-6 years' increase in the retirement requisites, with an average 3 -year delay. These women represent our 'treated group', while the remaining $26 \%$ make up the 'control group' (see Table 2).

Due to the joint effect of the new age/seniority requirements and of the heterogeneity in workers' ages and seniority at the time of the reform, the time profile of the delay is hump-shaped (see Table 3). The average increase is 3.5 years for women aged 56; about

Table 2 Delay in retirement (years) imposed on women in private employment by the reform

\begin{tabular}{lll}
\hline $\begin{array}{l}\text { Years of delay in retirement } \\
\text { imposed by the reform }\end{array}$ & Number of affected workers & $\begin{array}{l}\text { Percentage of } \\
\text { affected workers (\%) }\end{array}$ \\
\hline 0 & 6550 & 26 \\
1 & 5811 & 23 \\
2 & 2602 & 10 \\
3 & 3169 & 13 \\
4 & 1909 & 8 \\
5 & 3285 & 13 \\
6 & 1932 & 8 \\
Total & 25,258 & 100 \\
\hline
\end{tabular}

Source: Our simulations on INPS data 
Table 3 Size of control and treatment groups by age

\begin{tabular}{|c|c|c|c|}
\hline \multirow[t]{2}{*}{ Age } & \multirow{2}{*}{$\begin{array}{l}\text { Control group } \\
\text { Observations }\end{array}$} & \multicolumn{2}{|c|}{ Treatment group } \\
\hline & & Observations & Average number of years of delay \\
\hline 53 & 971 & 3349 & 1.833 \\
\hline 54 & 649 & 3337 & 2.268 \\
\hline 55 & 864 & 2894 & 2.755 \\
\hline 56 & 910 & 2564 & 3.500 \\
\hline 57 & 751 & 2185 & 3.996 \\
\hline 58 & 639 & 1746 & 4.339 \\
\hline 59 & 390 & 1409 & 4.292 \\
\hline 60 & 263 & 1205 & 2.601 \\
\hline 61 & 229 & 19 & 1.737 \\
\hline 62 & 332 & & \\
\hline 63 & 235 & & \\
\hline 64 & 194 & & \\
\hline 65 & 123 & & \\
\hline Total & 6550 & 18708 & \\
\hline Mean age & 57.01 & 55.74 & \\
\hline Mean delay (years) & & & 3.00 \\
\hline
\end{tabular}

Source: Our elaborations on INPS data

2 years for those under 56 and from 60 onwards and 4 years for those aged 57-59. Women aged $62+$ were unaffected by the reform. It should be noted that these requirements only refer to the rather generous (at least with respect to paid-in contributions) DB pension formula. Indeed, we did not simulate retirement according to the transitional DC option because very few women in the observed sample chose to retire with that formula, given the significant reduction in benefits with respect to the DB formula.

As for sick leave, about $33 \%$ (1.8 out of 5.2 million) of women in private employment had at least one in 2012. However, $82 \%$ of sick leave lasted less than 7 days (INPS health insurance archives, 2013 data, p. 4). On average, considering both 2011 and 2012, only $3 \%$ of the sample had a sick leave spell lasting more than 7 days, thus determining a credit of notional contributions.

Table 4 completes the picture with additional descriptive statistics. The table shows that the control and the treatment groups do not differ significantly in terms of sick leave spells, unemployment, seniority or the other observable individual or regional characteristics.

\section{Results}

In the estimations presented in this section, our dependent variable is the variation in the individuals' number of sick-leave weeks that occurred in year 2012 with respect to year 2011.

In our baseline specification (model 1), the set of regressors included a dummy capturing the time trend between 2011 and $2012(T)$ and a dummy identifying treated workers (Treated). The estimated coefficient of the latter variable captured the different reactions of individuals obliged to postpone retirement by the pension reform with respect to those not affected. We also controlled for a set of individual-specific 
Table 4 Descriptive statistics of the sample

\begin{tabular}{|c|c|c|c|c|c|}
\hline \multirow[b]{2}{*}{ Variables } & \multirow[b]{2}{*}{ Obs } & \multicolumn{2}{|c|}{ Year 2012} & \multicolumn{2}{|c|}{ Year 2011} \\
\hline & & Mean & Std. dev. & Mean & Std. dev. \\
\hline \multicolumn{6}{|l|}{ Treatment group } \\
\hline Weeks of sick leave & 18,708 & 0.12 & 1.00 & 0.11 & 0.91 \\
\hline Delay in retirement due to Monti-Fornero reform (years) & 18,708 & 3.00 & 1.77 & 0.00 & 0.00 \\
\hline Seniority (weeks) & 18,708 & 1389.99 & 424.95 & 1337.33 & 425.11 \\
\hline Sick-leave weeks in the whole career & 18,708 & 2.00 & 7.48 & 1.89 & 7.26 \\
\hline Sick-leave and unemployment weeks in the whole career & 18,708 & 16.14 & 36.52 & 16.03 & 36.45 \\
\hline Age & 18,708 & 55.74 & 2.15 & 54.74 & 2.15 \\
\hline Weekly wage (euro) & 18,708 & 481.02 & 243.65 & 473.59 & 238.63 \\
\hline Grandmothers & 18,708 & 0.41 & 0.49 & 0.41 & 0.49 \\
\hline With a sick spell in $\mathrm{t}-1$ & 18,708 & 0.03 & 0.16 & 0.03 & 0.16 \\
\hline North & 18,708 & 0.50 & 0.50 & 0.50 & 0.50 \\
\hline Centre & 18,708 & 0.37 & 0.48 & 0.37 & 0.48 \\
\hline South & 18,708 & 0.13 & 0.34 & 0.13 & 0.34 \\
\hline \multicolumn{6}{|l|}{ Control group } \\
\hline Weeks of sick leave & 6550 & 0.11 & 0.98 & 0.11 & 0.92 \\
\hline Seniority (weeks) & 6550 & 1418.41 & 679.83 & 1365.60 & 679.59 \\
\hline Sick-leave weeks in the whole career & 6550 & 1.43 & 5.57 & 1.33 & 5.38 \\
\hline Sick-leave and unemployment weeks in the whole career & 6550 & 11.95 & 34.88 & 11.85 & 34.84 \\
\hline Age & 6550 & 57.01 & 3.23 & 56.01 & 3.23 \\
\hline Weekly wage (euro) & 6550 & 477.92 & 261.54 & 463.30 & 227.80 \\
\hline Grandmothers & 6550 & 0.43 & 0.50 & 0.43 & 0.50 \\
\hline With a sick spell in $\mathrm{t}-1$ & 6550 & 0.02 & 0.15 & 0.02 & 0.15 \\
\hline North & 6550 & 0.54 & 0.50 & 0.54 & 0.50 \\
\hline Centre & 6550 & 0.35 & 0.48 & 0.35 & 0.48 \\
\hline South & 6550 & 0.11 & 0.31 & 0.11 & 0.31 \\
\hline
\end{tabular}

Source: Our elaborations

characteristics, i.e. the individuals' variations in seniority, in the interaction between seniority and age, in the number of weeks of notional contribution during the whole (observed) working life, in the age squared, in the logarithm of the gross weekly wage and in the regional unemployment rate. All seniority variables were measured at the beginning of each year. As usual for an FD setting, the effect of time-invariant regressors cancels out and the influence of the variation in age could not be separated from the time trend.

In model 1, we observed a negative time trend in sick-leave absences and a positive effect of the treatment. The former was significant at usual standard significance levels. The effect of the other control variables was generally in line with previous findings: an increase in seniority corresponded to higher absences, but here, such an effect depended negatively on age; an increase in notional contribution periods reduced the weeks of absence, probably because they were excluded from effective seniority computation and an increase in gross wage and in regional unemployment rates was negatively correlated with absences.

In model 2, we tested whether grandmothers behave differently from nongrandmothers by adding an interaction term between the dummy Treated and the 
dummy identifying grandmothers (Grandmothers). We found that the coefficient of this interaction dummy was positive and statistically significant. Grandmothers on average reacted to the reform by increasing their weeks of sick leave, while non-grandmothers showed no significant reaction to the reform.

In model 3, we accounted for personal sick-leave histories as we interpreted sickleave spells in the pre-reform setting as a proxy for a general worsening of health conditions. We used the dummy identifying individuals with a sick-leave spell in 2011, and we made it interact with the time trend $(T)$, the treatment dummy (Treated) and the interaction dummy (Treated"grandmothers). We found relevant differences in the behaviour of the two groups. First, the statistical significance of the negative time trend in sick leave persisted only for the individuals with no sick-leave spell in 2011. Second, women observed to have taken a sick-leave spell in 2011 actually reacted to the treatment by increasing their sick leave in 2012. Women with no sick-leave spells in 2011 reacted to the treatment much less and only if they were grandmothers. Our interpretation is that among women who had not yet experienced a sick-leave spell in 2011, and could then be considered to be in a relatively better health condition, a reaction to the delayed retirement was observed only when they were involved in caring activities with their grandchildren (Table 5).

Table 5 Regression results I: FD-dependent variable: variation in weeks of sick leave between 2011 and 2012

\begin{tabular}{|c|c|c|c|}
\hline & Model 1 (b/se) & Model 2 (b/se) & Model 3 (b/se) \\
\hline$T$ & $-0.377^{* *}(0.152)$ & $-0.413^{* * *}(0.155)$ & \\
\hline Treated & $0.015(0.015)$ & $-0.005(0.015)$ & \\
\hline Treated $^{*}$ grandmother & & $0.048^{* * *}(0.015)$ & \\
\hline $\mathrm{T}_{\text {sick in } 2011}$ & & & $-0.227(0.211)$ \\
\hline$T_{\text {not sick in } 2011}$ & & & $-0.393^{* *}(0.154)$ \\
\hline Treated $_{\text {sick in } 2011}$ & & & $0.389^{* *}(0.182)$ \\
\hline Treated $_{\text {not sick in } 2011}$ & & & $-0.016(0.015)$ \\
\hline 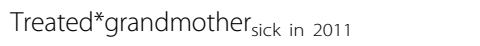 & & & $0.120(0.197)$ \\
\hline 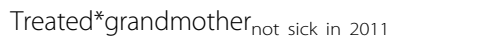 & & & $0.044^{* * *}(0.015)$ \\
\hline$\Delta$ Seniority & $0.003^{* * *}(0.001)$ & $0.004^{* * *}(0.001)$ & $0.003^{* * *}(0.001)$ \\
\hline$\Delta$ Seniority*age & $-0.000^{* * *}(0.000)$ & $-0.000^{* * *}(0.000)$ & $-0.000^{* * *}(0.000)$ \\
\hline$\Delta$ Notional seniority & $-0.863^{* * *}(0.018)$ & $-0.863^{* * *}(0.018)$ & $-0.926^{* * *}(0.024)$ \\
\hline$\Delta \mathrm{Age}^{2}$ & $0.005^{* * *}(0.001)$ & $0.005^{* * *}(0.001)$ & $0.005^{* * *}(0.001)$ \\
\hline$\Delta \log ($ wage) & $-0.195^{* * *}(0.070)$ & $-0.197^{* * *}(0.070)$ & $-0.205^{* * *}(0.070)$ \\
\hline$\Delta$ Regional unemployment rate & $-0.003(0.008)$ & $-0.002(0.008)$ & $-0.001(0.008)$ \\
\hline Adjusted $R$-square & 0.391 & 0.391 & 0.394 \\
\hline N & 25,258 & 25,258 & 25,258 \\
\hline \multicolumn{4}{|l|}{ Tests ( $P$ values) } \\
\hline $\mathrm{T}_{\text {sick in } 2011}=\mathrm{T}_{\text {not sick in } 2011}$ & & & 0.2555 \\
\hline Treated $_{\text {sick in } 2011}=$ Treated $_{\text {not sick in } 2011}$ & & & 0.0264 \\
\hline Treated $_{i}+\left(\right.$ Treated $^{*}$ grandmother $\left._{i}\right)=0$ & & 0.0183 & \\
\hline$i=$ sick in 2011 & & & 0.0120 \\
\hline$i=$ not sick in 2011 & & & 0.1147 \\
\hline
\end{tabular}

Note: Significance levels: ${ }^{*} 0.10,{ }^{* *} 0.05$, and ${ }^{* * *} 0.01$. Robust errors clustered at level of groups with uniform age, sick leave in 2011, income, seniority level and region 
In model 4, we shed further light on the issue, investigating whether the income level of the household played a role in sick-leave behaviour; to this purpose, on the basis of their gross wage in 2011, we split the sample into three groups: low-, medium- and high-income individuals. Interestingly, estimated coefficients preserved their statistical significance only in the low-income sample. In particular, the results related to the women with no sick-leave spells in 2011 supported the idea that sick leave is an option mainly for grandmothers without sufficient economic resources to buy care in the market.

Finally, in model 5, we differentiated between the reactions of grandmothers to the treatment on the basis of the coverage rates of services for children in the region of residence. We divided the regions of residence into three groups: low, medium and high coverage-rate regions. ${ }^{8}$ Among individuals with no sick-leave spells in 2011, we found evidence of a stronger reaction to the reform from low-income grandmothers living in low coverage-rate regions. This result supported the idea that not only income levels but also the availability of (public and private) childcare services influence the grandmothers' recourse to sick leave. The results related to individuals with a sickleave spell in 2011 were not so reliable, due to the small sample size of many of the sub-groups of grandmothers identified in Table 6 on the basis of their income and of the coverage rate of services for children in their region of residence.

We then used the delay in retirement (Delay) in place of the dummy identifying treated workers (Treated). The delay is the number of years of postponed retirement induced by the reform (values are rounded up to the nearest integer). For the control group, the variable Delay is zero. As above, we tried different specifications; the results are shown in Tables 7 and 8. This new set of regressions confirmed previous findings and showed that the effect of the treatment was actually proportional to the number of years of delay in retirement at least for the group of individuals that had not already taken sick leave in 2011.

In order to quantify the effects previously described, we ran some simulations starting from the estimated coefficients in models 5 and 6 . For women observed to have already been on sick leave in 2011, the average number of sick-leave weeks was 4.12 . The model predicted a decrease in sick-leave absences of about -3.55 weeks for individuals not affected by the reform, which becomes -3.16 for those affected by the reform.

Concerning the individuals not sick in 2011, our model predicted an increase in sickleave absences of about 0.094 weeks for individuals not affected by the reform. As for the workers obliged by the pension reform to postpone retirement, the increase was reduced to 0.078 weeks for non-grandmothers, while it increased to 0.122 weeks for grandmothers. These numbers, although appearing very small, hide important variations in relative terms, for example, within the group of women with no sick leave in 2011, the predicted number of weeks of sick leave for our sample of treated grandmothers was about $30 \%$ higher than for the women not affected by the reform. Among low-income earners, the predicted variation was on average equal to 0.083 weeks for non-treated and rose to $0.19(+130 \%)$ for grandmothers obliged to postpone retirement and living in regions with low provision of care facilities for children.

Furthermore, as we could only dispose of information on sick-leave spells lasting more than one week, our calculations probably underestimated the phenomenon.

A set of robustness checks, including a sensitivity test for the assumptions about the month of birth, a strict exogeneity test, a sensitivity test of the results to the timing of 
Table 6 Regression results I. FD-dependent variable: variation in weeks of sick leave between 2011 and 2012

\begin{tabular}{|c|c|c|c|c|c|c|}
\hline & & Model 4 & & & Model 5 & \\
\hline & Low income (b/se) & Medium income (b/se) & High income (b/se) & Low income (b/se) & Medium income (b/se) & High income (b/se) \\
\hline $\mathrm{T}_{\text {sick in } 2011}$ & $-0.581 * *(0.277)$ & $0.396(0.494)$ & $0.512(0.582)$ & $-0.583^{* *}(0.277)$ & $0.376(0.491)$ & $0.529(0.594)$ \\
\hline $\mathrm{T}_{\text {not sick in } 2011}$ & $-0.679^{* * *}(0.242)$ & $0.175(0.339)$ & $-0.020(0.187)$ & $-0.684^{* * *}(0.241)$ & $0.167(0.337)$ & $0.050(0.184)$ \\
\hline Treated $_{\text {sick in } 2011}$ & $0.540^{* *}(0.235)$ & $0.188(0.312)$ & $-0.040(0.521)$ & $0.539 * *(0.235)$ & $0.190(0.312)$ & $-0.013(0.526)$ \\
\hline Treated $_{\text {not sick in } 2011}$ & $0.016(0.025)$ & $-0.040(0.033)$ & $-0.007(0.015)$ & $0.016(0.025)$ & $-0.040(0.033)$ & $-0.007(0.015)$ \\
\hline Treated $^{*}$ grandmother ${ }_{\text {sick in }} 2011$ & $0.032(0.287)$ & $0.104(0.303)$ & $0.828(0.550)$ & & & \\
\hline 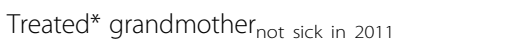 & $0.063^{* *}(0.028)$ & $0.052(0.032)$ & $0.013(0.016)$ & & & \\
\hline \multicolumn{7}{|l|}{ Treated*arandmother } \\
\hline Sick in 2011, low-coverage region & & & & $-0.064(0.343)$ & $0.309(0.463)$ & $2.324^{* *}(1.025)$ \\
\hline Sick in 2011, medium-coverage region & & & & $-0.079(0.567)$ & $-0.525^{* *}(0.244)$ & $0.404(0.682)$ \\
\hline Sick in 2011 , high-coverage region & & & & $0.214(0.477)$ & $0.288(0.401)$ & $0.175(0.677)$ \\
\hline Not sick in 2011, low-coverage region & & & & $0.090^{* *}(0.041)$ & $0.027(0.044)$ & $0.025(0.025)$ \\
\hline Not sick in 2011, medium-coverage region & & & & $0.036(0.037)$ & $0.033(0.055)$ & $-0.013(0.017)$ \\
\hline Not sick in 2011, high-coverage region & & & & $0.041(0.044)$ & $0.098^{*}(0.057)$ & $0.006(0.016)$ \\
\hline Adjusted R-square & 0.515 & 0.315 & 0.240 & 0.515 & 0.316 & 0.246 \\
\hline N & 8420 & 8419 & 8419 & 8420 & 8419 & 8419 \\
\hline \multicolumn{7}{|l|}{ Tests ( $P$ values) } \\
\hline $\mathrm{T}_{\text {sick in } 2011}=\mathrm{T}_{\text {not sick in } 2011}$ & 0.5105 & 0.5063 & 0.3262 & 0.5042 & 0.5272 & 0.3777 \\
\hline Treated $_{\text {sick in } 2011}=$ Treated $_{\text {not sick in } 2011}$ & 0.0269 & 0.4679 & 0.9493 & 0.0271 & 0.4633 & 0.9907 \\
\hline \multicolumn{7}{|l|}{ Treated $_{i}+\left(\right.$ Treated $^{*}$ grandmother $\left._{i}\right)=0$} \\
\hline$i=$ sick in 2011 & 0.0459 & 0.4413 & 0.1424 & & & \\
\hline$i=$ not sick in 2011 & 0.0127 & 0.7596 & 0.7479 & & & \\
\hline
\end{tabular}


Table 6 Regression results I. FD-dependent variable: variation in weeks of sick leave between 2011 and 2012 (Continued)

\begin{tabular}{|c|c|c|c|}
\hline \multicolumn{4}{|l|}{ In low-coverage regions } \\
\hline$i=$ sick in 2011 & 0.1836 & 0.3415 & 0.0191 \\
\hline$i=$ not sick in 2011 & 0.0160 & 0.8046 & 0.5047 \\
\hline \multicolumn{4}{|c|}{ In medium-coverage regions } \\
\hline$i=$ sick in 2011 & 0.4146 & 0.3232 & 0.6225 \\
\hline$i=$ not sick in 2011 & 0.1753 & 0.9045 & 0.3176 \\
\hline \multicolumn{4}{|c|}{ In high-coverage regions } \\
\hline$i=$ sick in 2011 & 0.1069 & 0.2907 & 0.7865 \\
\hline$i=$ not sick in 2011 & 0.2194 & 0.3386 & 0.9539 \\
\hline
\end{tabular}

Note: Significance levels: ${ }^{*} 0.10,{ }^{* *} 0.05$, and ${ }^{* *} 0.01$. Robust errors clustered at level of groups with uniform age, sick leave in 2011 , income, seniority level and region. All the regressions control for variations in

seniority, in the interaction between seniority and age, in the number of weeks of notional contribution during the whole (observed) working life, in the age squared, in the logarithm of the gross weekly wage and in

the regional unemployment rate 
Table 7 Regression results II. FD-dependent variable: variation in weeks of sick leave between 2011 and 2012

\begin{tabular}{|c|c|c|c|}
\hline & $\begin{array}{l}\text { Model } 1 \\
\text { b/se }\end{array}$ & $\begin{array}{l}\text { Model } 2 \\
\text { b/se }\end{array}$ & $\begin{array}{l}\text { Model } 3 \\
\text { b/se }\end{array}$ \\
\hline $\bar{T}$ & $-0.329^{* *}(0.145)$ & $-0.359^{* *}(0.146)$ & \\
\hline Delay & $0.003(0.003)$ & $-0.003(0.003)$ & \\
\hline Delay* ${ }^{*}$ randmother & & $0.017^{* * *}(0.005)$ & \\
\hline $\mathrm{T}_{\text {sick in } 2011}$ & & & $0.023(0.197)$ \\
\hline $\mathrm{T}_{\text {not sick in } 2011}$ & & & $-0.343^{* *}(0.145)$ \\
\hline 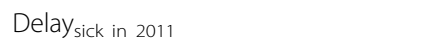 & & & $0.043(0.040)$ \\
\hline Delay $_{\text {not sick in } 2011}$ & & & $-0.005(0.003)$ \\
\hline 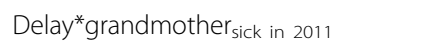 & & & $0.032(0.049)$ \\
\hline 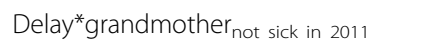 & & & $0.015^{* * *}(0.004)$ \\
\hline$\Delta$ Seniority & $0.003^{* * *}(0.001)$ & $0.003^{* * *}(0.001)$ & $0.003^{* * *}(0.001)$ \\
\hline$\Delta$ Seniority*age & $-0.000^{* * *}(0.000)$ & $-0.000^{* * *}(0.000)$ & $-0.000^{* * *}(0.000)$ \\
\hline$\Delta$ Notional seniority & $-0.863^{* * *}(0.018)$ & $-0.864^{* * *}(0.018)$ & $-0.927^{* * *}(0.023)$ \\
\hline$\Delta \mathrm{Age}^{2}$ & $0.005^{* * *}(0.001)$ & $0.005^{* * *}(0.001)$ & $0.005^{* * *}(0.001)$ \\
\hline$\Delta$ Log (wage) & $-0.196^{* * *}(0.069)$ & $-0.198^{* * *}(0.069)$ & $-0.209^{* * *}(0.069)$ \\
\hline$\Delta$ Regional unemployment rate & $-0.003(0.008)$ & $-0.002(0.008)$ & $-0.001(0.008)$ \\
\hline Adjusted $R$-square & 0.391 & 0.391 & 0.394 \\
\hline$N$ & 25,258 & 25,258 & 25,258 \\
\hline \multicolumn{4}{|l|}{ Tests ( $P$ values) } \\
\hline$T_{\text {sick in } 2011}=T_{\text {not sick in } 2011}$ & & & 0.0067 \\
\hline Delay $_{\text {sick in } 2011}=$ Delay $_{\text {not sick in } 2011}$ & & & 0.2375 \\
\hline Delay $_{i}+\left(\right.$ Delay $^{*}$ grandmother $\left._{i}\right)=0$ & & 0.0026 & \\
\hline$i=$ sick in 2011 & & & 0.1165 \\
\hline$i=$ not sick in 2011 & & & 0.0163 \\
\hline
\end{tabular}

Note: Significance levels: ${ }^{*} 0.10,{ }^{* *} 0.05$, and ${ }^{* * *} 0.01$. Robust errors clustered at level of groups with uniform age, sick leave in 2011, income, seniority level and region

retirement and a placebo test on the effects of the treatment, is described and reported in the appendices (Additional file 2).

\section{Conclusions}

The paper analyses the response of women, in terms of sick-leave utilisation, to a pension reform that restricts access conditions to retirement. To the best of our knowledge, it is the first attempt of this kind.

We apply the analysis to Italy, which provides a particularly good case study, almost a 'quasi-natural' experiment, for three different reasons. First, the reform-undertaken under the threat of a financial crisis and strongly advocated by international institutions as a public expenditure stabiliser-was quite radical and only allowed for a very short transition period. In this sense, the reform was largely unanticipated by the public. Second, women, who had been largely sheltered from the effects of previous reforms, experienced the most extensive postponement of their retirement age, because the reform drastically reduced the so-called seniority pensions, which provided an extremely favourable access to early retirement. Third, Italy suffers from a lack of public care facilities, and women traditionally are called upon to compensate this deficiency within the family. 
Table 8 Regression results I. FD-dependent variable: variation in weeks of sick leave between 2011 and 2012

\begin{tabular}{|c|c|c|c|c|c|c|}
\hline & & Model 4 & & & Model 5 & \\
\hline & Low income (b/se) & Medium income (b/se) & High income (b/se) & Low income (b/se) & Medium income (b/se) & High income (b/se) \\
\hline $\mathrm{T}_{\text {sick in } 2011}$ & $-0.121(0.289)$ & $0.543(0.408)$ & $0.496(0.441)$ & $-0.114(0.284)$ & $0.551(0.405)$ & $0.489(0.478)$ \\
\hline $\mathrm{T}_{\text {not sick in } 2011}$ & $-0.462^{*}(0.237)$ & $0.162(0.313)$ & $-0.023(0.172)$ & $-0.460^{*}(0.236)$ & $0.143(0.310)$ & $0.024(0.171)$ \\
\hline Delay $_{\text {sick in } 2011}$ & $0.058(0.049)$ & $0.017(0.064)$ & $-0.029(0.084)$ & $0.058(0.049)$ & $0.010(0.064)$ & $-0.031(0.087)$ \\
\hline 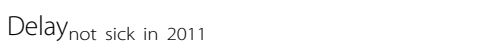 & $-0.003(0.005)$ & $-0.006(0.007)$ & $-0.004(0.003)$ & $-0.003(0.005)$ & $-0.007(0.007)$ & $-0.004(0.003)$ \\
\hline Delay*grandmother ${ }_{\text {sick in } 2011}$ & $0.009(0.067)$ & $0.005(0.074)$ & $0.272^{*}(0.143)$ & & & \\
\hline 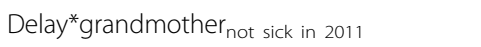 & $0.018^{* *}(0.008)$ & $0.014(0.009)$ & $0.009(0.005)$ & & & \\
\hline \multicolumn{7}{|l|}{ Delay*grandmother } \\
\hline sick in 2011, low-coverage region & & & & $0.037(0.093)$ & $-0.007(0.096)$ & $0.514^{* *}(0.258)$ \\
\hline sick in 2011, medium-coverage region & & & & $-0.027(0.114)$ & $-0.171^{* *}(0.070)$ & $0.268(0.196)$ \\
\hline sick in 2011, high-coverage region & & & & $0.001(0.117)$ & $0.073(0.102)$ & $0.048(0.163)$ \\
\hline not sick in 2011, low-coverage region & & & & $0.029^{* *}(0.011)$ & $0.000(0.010)$ & $0.014(0.009)$ \\
\hline not sick in 2011, medium-coverage region & & & & $0.007(0.011)$ & $0.020(0.019)$ & $-0.003(0.005)$ \\
\hline not sick in 2011, high-coverage region & & & & $0.011(0.012)$ & $0.029^{*}(0.016)$ & $0.005(0.005)$ \\
\hline Adjusted R-square & 0.515 & 0.315 & 0.240 & 0.515 & 0.316 & 0.246 \\
\hline N & 8420 & 8419 & 8419 & 8420 & 8419 & 8419 \\
\hline \multicolumn{7}{|l|}{ Tests ( $P$ values) } \\
\hline $\mathrm{T}_{\text {sick in } 2011}=\mathrm{T}_{\text {not sick in } 2011}$ & 0.0373 & 0.1648 & 0.1648 & 0.0308 & 0.1339 & 0.2495 \\
\hline Treated $_{\text {sick in } 2011}=$ Treated $_{\text {not sick in } 2011}$ & 0.2161 & 0.7218 & 0.7218 & 0.2146 & 0.8000 & 0.7542 \\
\hline \multicolumn{7}{|l|}{ Treated $_{i}+\left(\right.$ Treated $^{*}$ grandmother $\left._{i}\right)=0$} \\
\hline$i=$ sick in 2011 & 0.2923 & 0.7213 & 0.7913 & & & \\
\hline$i=$ not sick in 2011 & 0.0424 & 0.3622 & 0.3622 & & & \\
\hline
\end{tabular}


Table 8 Regression results I. FD-dependent variable: variation in weeks of sick leave between 2011 and 2012 (Continued)

\begin{tabular}{|c|c|c|c|}
\hline \multicolumn{4}{|l|}{ In low-coverage regions } \\
\hline$i=$ sick in 2011 & 0.3418 & 0.9773 & 0.0694 \\
\hline$i=$ not sick in 2011 & 0.0230 & 0.4894 & 0.2782 \\
\hline \multicolumn{4}{|c|}{ In medium-coverage regions } \\
\hline$i=$ sick in 2011 & 0.7705 & 0.0554 & 0.2591 \\
\hline$i=$ not sick in 2011 & 0.7158 & 0.4829 & 0.2081 \\
\hline \multicolumn{4}{|c|}{ In high-coverage regions } \\
\hline$i=$ sick in 2011 & 0.5872 & 0.4250 & 0.8862 \\
\hline$i=$ not sick in 2011 & 0.5158 & 0.1429 & 0.8708 \\
\hline
\end{tabular}

Note: Significance levels: ${ }^{*} 0.10,{ }^{* *} 0.05$, and ${ }^{* *} 0.01$. Robust errors clustered at level of groups with uniform age, sick leave in 2011 , income, seniority level and region. All the regressions control for variations in

seniority, in the interaction between seniority and age, in the number of weeks of notional contribution during the whole (observed) working life, in the age squared, in the logarithm of the gross weekly wage and in

the regional unemployment rate 
We found evidence of women's response to changes in pension rules. Such a response differed according to their past sick-leave records and income levels. Lowincome female workers who in 2011 had already experienced a sick-leave spell, and were forced by the pension reform to postpone retirement, appeared to increase the total amount of time on sick leave. Low-income women who did not have a sick-leave spell in 2011 behaved in the same manner but less intensively and only if they benefited from maternity leave in their youth (our 'conjectured' grandmothers), presumably engaged in care activities for their grandchildren. For the latter group, moreover, the measured increase was proportional to the number of years of pension delay introduced by the 2011 reform. This evidence is particularly significant for women living in regions with low provision of care services for children.

We cannot say (and we do not want to suggest) that our findings concerning grandmothers point to opportunistic behaviour. Indeed, a careful consideration of our results seems to support a different view, i.e. that given the abovementioned chronic lack of well-structured, high-quality care facilities, and the necessity for middle-aged women to compensate for them with informal care, it is likely that sick leave provided a kind of last resort response.

This exercise calls for wide-ranging policy considerations. In particular, when a fundamental social reform is introduced with great speed, in order to immediately reduce public pension expenditure and to improve its medium-long-term sustainability, it is only natural for it to produce negative collateral effects. When, as was the case for Italy prior to the reform, the pension system is used as a catch-all remedy for various kinds of social imbalances, even a radical reform risks losing effectiveness if it is not accompanied by parallel measures meant to fill the gaps. True, this can hardly be done in an emergency, although some relief could be provided by issuing ad hoc vouchers aimed at filling specific gaps, like the ones in care services that have been highlighted in the paper.

Our final point is that the ultimate success of a pension reform depends on many factors. Information and financial literacy that boost understanding of the reforms certainly facilitate their acceptance (Boeri and Tabellini 2012; Fornero 2015). A key role is also played by welfare policies specifically aimed to alleviate the burden of care activities that fall on women, particularly in Mediterranean countries. This requires massive structural improvements in care facilities. Working grandmothers would be less inclined to take sick leave if families could rely on public financial help to substitute at least the most important care activities they still heavily perform.

\section{Endnotes}

${ }^{1}$ No estimate for Italy is available but for Norway, Markussen (2012) estimated that a $1 \%$ increase in sick-leave rates leads to a drop in earnings of about $1.2 \%$ in the following 2 years.

${ }^{2}$ Illness episodes are automatically registered in the monthly individual records (denunce individuali mensili, EMens) and reported in the INPS 'Estratti Conto' archive; to get notional payroll accreditation, workers have to apply instead.

${ }^{3}$ For the $0-3$ age group, the 2009 coverage rate of public structures is $13 \%$, ranging from 3 in Campania to 31 in Emilia-Romagna (Istituto degli Innocenti 2013). 
${ }^{4}$ Since 2012, the Estratti Conto archive has been publicly available for research.

See: http://www.cliclavoro.gov.it/Barometro-Del-Lavoro/Pagine/Microdati-per-laricerca.aspx.

${ }^{5}$ Although we cannot reconstruct their precise number, we can indirectly assume this to be rather limited because of, first, the traditionally low mobility characterising the Italian labour market; second, the obstacles to the transition from public to private employment or from self-employment to a dependent position.

${ }^{6}$ From an initial sample of 7,169,385 contribution periods, we dropped: very early starters (before the age of 15); workers having special pension provisions or exceeding 96 weeks of notional payroll or having made no contribution in 2012 or wage 'outliers'; having more than 52 weeks of seniority in 2011 and 2012 and aged 65+ with less than 15 years' contribution by 2012 . We also excluded individuals who were unemployed (mobilità, cassa integrazione e disoccupazione) in 2012. More information is available upon request.

${ }^{7}$ The sensitivity analysis of this assumption can be found in Additional file 2: Tables S2 and S3.

${ }^{8}$ As a proxy for the overall intensity of formal care services, we used the coverage rate of care services for children aged $0-2$ by region measured at 1/9/2011 provided by the Istituto degli Innocenti (2013), p. 35 (Tavola 2-Tasso di copertura nei servizi educativi che accolgono bambini $0-2$ al 1.9.2011).

\section{Additional files}

Additional file 1: Normative appendix. (DOC $29 \mathrm{~kb}$ )

Additional file 2: Robustness checks (Wooldridge 2002). (DOCX 62 kb)

\section{Competing interests}

The IZA Journal of European Labor Studies is committed to the IZA Guiding Principles of Research Integrity. The authors declare that they have observed these principles.

\section{Acknowledgements}

We thank Ronald Oaxaca, Arthur van Soest and an anonymous referee for their constructive comments and suggestions. We also acknowledge useful discussions with participants in Le Havre ('Ageing, Economic Uncertainty, Savings and Long-run Governance of Pension Schemes', 16-17 April 2015) and Paris-Dauphine conferences ('13th International Workshop in Pensions, Insurance and Savings', 28-29 May 2015). Funding from the project 'Wealth at Retirement and Savings Adequacy' (WeRSA), European Commission DG Employment, Social Affairs and Inclusion, Grant Agreement No. VS/2013/0208 is gratefully acknowledged.

Responsible editor: Martin Kahanec

\footnotetext{
Author details

${ }^{1}$ University of Turin and CeRP-Collegio Carlo Alberto, Corso Unione Sovietica 218bis, 10134 Torino, Italy. ${ }^{2}$ The Ragnar Frisch Centre for Economic Research, Gaustadalleen 21, 0349 Oslo, Norway.
}

Received: 8 September 2015 Accepted: 7 January 2016

Published online: 18 January 2016

\section{References}

Andreassen L, Kornstad T (2010) What determines transitions to sick leave? Dipartimento di Economia 'S. Cognetti de Martiis' Working paper n.12/2010

Attanasio OP, Rohwedder S (2003) Pension wealth and household saving: evidence from pension reforms in the United Kingdom. Am Econ Rev 93(5):1499-1521

Belloni M, Alessie R (2009) The importance of financial incentives on retirement choices: new evidence for Italy. Labour Econ 16(5):578-588

Boeri T, Tabellini G (2012) Does information increase political support for pension reform? Public Choice 150:327-362

Borella M, Coda Moscarola F (2006) Distributive properties of pension systems: a simulation of the Italian transition from defined benefit to notional defined contribution. Giornale degli Economisti e Annali di Economia 65(1):95-126

Borella M, Coda Moscarola F (2011) Microsimulation of pension reforms: behavioural versus nonbehavioural approach. JPEF 9(4):583-607 
Buyse T, Heylen F, Van de Kerckhove R (2013) Pension reform, employment by age, and long-run growth. J Popul Econ 26(2):769-809

Colombino U, Hernes E, Locatelli M, Strøm S (2011) Pension reforms, liquidity constraints and labour supply responses. JPEF 10(1):53-74

Del Boca D, Locatelli M, Vuri D (2005) Child-care choices by working mothers: the case of Italy. Rev Econ Househ 3(4):453-477 Fornero E (2014) Reforming labor markets: reflections of an economist who (unexpectedly) became the Italian Minister of Labor. J Eur Labor Stud. 2013;2(20)

Fornero E (2015) Economic-financial literacy and (sustainable) pension reforms: why the former is a key ingredient for the latter. Bankers, Markets and Investors 134:6-16

Fornero E, Lusardi A, Monticone C (2010) Adequacy of saving for old age in Europe. In: Van Soest, A, Bovenberg L, Zaidi A (eds), Ageing, health and pensions in Europe: An economic perspective, Macmillian Palgrave, London

Ichino A, Riphahn RT (2005) The effect of employment protection on worker effort: absenteeism during and after probation. J Eur Econ Assoc 3:120-143

Ichino A, Sanz de Galdeano A (2005) Reconciling motherhood and work: evidence from time use data in three countries. In: Hamermesh D, Pfann G (eds) The economics of time use. Elsevier, Amsterdam

INPS (2013) Rapporto 2012 sui certificati medici e sugli eventi di malattia. Report of the Istituto Nazionale della Previdenza Sociale, Roma

Istituto degli Innocenti (2013) Monitoraggio del Piano di sviluppo dei servizi socio-educativi per la prima infanzia, Report 31 December 2012

Johansson P, Palme M (1996) Do economic incentives affect work absence? Empirical evidence using Swedish micro data. J Pub Econ 59(2):195-218

Johansson P, Palme M (2002) Assessing the effect of public policy on worker absenteeism. J Hum Resour 37(2):381-409 Keck W, Saraceno C (2008) Grandchildren in Germany and in Italy, an exploration. In: Leira A, Saraceno C (eds) Childhood: Changing contexts, Book Series: Comparative Social Research, 35. Emerald, United Kingdom

Leigh JP (1985) The effects of unemployment and the business cycle on absenteeism. J Econ Bus 37(2):159-170 Markussen S (2012) The individual cost of sick-leave. J Popul Econ 25(4):1287-1306

Moreau M, Valente F, Mak R, Pelfrene E, de Smet V, de Backer G, Kornitzer M (2004) BMJ occupational stress and incidence of sick-leave in the Belgian workforce: the Belstress study. J Epidemiol Commun H 58(6):507-516

Ragioneria Generale dello Stato (2014) Le tendenze di medio-lungo periodo del sistema pensionistico e socio-sanitario-aggiornamento 2014, Rapporto n.15

Scoppa V (2010) Worker absenteeism and incentives: evidence from Italy. Managerial Dec Econ 31(8):503-515

Scoppa V, Vuri D (2014) Absenteeism, unemployment and employment protection legislation: evidence from Italy. IZA J Labor Econ 3(1):1-15

Wooldridge J (2002) Econometric analysis of cross section and panel data. The MIT Press, Cambridge, Massachusetts

Submit your manuscript to a SpringerOpen ${ }^{\odot}$ journal and benefit from:

- Convenient online submission

- Rigorous peer review

- Immediate publication on acceptance

- Open access: articles freely available online

- High visibility within the field

Retaining the copyright to your article

Submit your next manuscript at $>$ springeropen.com 